\title{
PENGARUH SIMULASI PELATIHAN BANTUAN HIDUP DASAR (BHD) TERHADAP MOTIVASI DAN SKILL RESUSITASI JANTUNG PARU (RJP) PADA KARANG TARUNA RW 06 KAMPUNG UTAN KELURAHAN KRUKUT DEPOK
}

\author{
Sri Muniarti ${ }^{1}$ Santi Herlina ${ }^{2}$ \\ Program Studi S1 Keperawatan Fakultas Ilmu Kesehatan \\ Universitas Pembangunan Nasional "Veteran" Jakarta \\ Email : santiherlina@upnvj.ac.id
}

\begin{abstract}
ABSTRAK
Angka kejadian Out of Hospital Cardiac Arrest (OHCA) terjadi di rumah dan di tempat umum sebanyak $80 \%$. Kejadian OHCA dapat ditangani dengan melakukan tindakan RJP saat awal serangan, namun permasalahannya adalah ketidaktahuan orang awam mengenai cara menolong atau tehnik RJP yang tepat. Untuk itu pelatihan BHD di komunitas Karang Taruna dinilai penting untuk dilakukan agar terbentuk bystander di lingkungan masyarakat. Tujuan penelitian ini untuk menganalisis pengaruh simulasi pelatihan BHD terhadap motivasi dan skill RJP. Desain penelitian menggunakan quasi experiment with one group dengan pretest-posttest. Sampel berjumlah 23 responden yang merupakan anggota Katar RW 06, metode pengumpulan data menggunakan kuesioner dan lembar observasi. Analisa data menggunakan uji T-Independent, T-Dependent, Wilcoxon Sign Test, dan Korelasi Pearson. Hasil penelitian uji T-Dependent didapatkan nilai $p$ value $<0.05$. Kesimpulan menunjukan bahwa terdapat pengaruh yang signifikan antara simulasi BHD terhadap motivasi $(p=0.000)$, skill $(\mathrm{p}=0.000)$, dan pengetahuan $(\mathrm{p}=0.000)$ di RW 06 Krukut. Saran agar pihak Karang Taruna menggunakan pengetahuan dan pengalaman yang didapat dari pelatihan simulasi BHD sehingga dapat meningkatkan motivasi dan skill RJP untuk menolong korban henti jantung, untuk peneliti selanjutnya dapat meneliti faktor lain yang dapat meningkatkan skill dan motivasi.
\end{abstract}

Kata Kunci: BHD, Karang Taruna, Motivasi, Simulasi RJP

\section{ABSTRACT}

Out of Hospital Cardiac Arrest (OHCA) incidence occurs at home and in public places as much as $80 \%$. OHCA events can be handled by carrying out CPR actions at the beginning of the attack, but the problem is the layman's ignorance about how to help or the right RJP technique. For this reason BHD training in the Karang Taruna community is considered important to be done so that bystander is formed in the community. The purpose of this study was to analyze the effect of BHD training simulations on CPR motivation and skills. The study design used a quasi experiment with one group with the pretest-posttest. The sample was 23 respondents who were members of Katar $R W 06$, the method of collecting data using questionnaires and observation sheets. Data analysis using the T-Independent test, T-Dependent, Wilcoxon Sign Test, and Pearson Correlation. The results of the T-Dependent test obtained $p$ value $<0.05$. Conclusions show that there is a significant influence between BHD simulation on motivation $(p=0.000)$, skill $(p=0,000)$, and knowledge $(p=$ 0,000) in RW 06 Krukut. Suggestions for Karang Taruna to use the knowledge and experience gained from BHD simulation training so as to increase RJP motivation and skills to help victims of cardiac arrest, for further researchers to examine other factors that can improve skills and motivation

Keywords: BLS, Simulation of CPR, Motivation 
Alamat korespondensi: Fakultas Ilmu Kesehatan UPN Veteran Jakarta

Email: santiherlina@upnvj.ac.id

\section{PENDAHULUAN}

Henti jantung atau cardiac arrest adalah penghentian mendadak aktivitas pemompaan jantung yang efektif, yang menimbulkan berhentinya sirkulasi. Penyebab henti jantung yaitu infak miokardium, gagal jantung, dan disritmia, (Patricia, 2013). Cardiac Arrest merupakan kasus kegawatdaruratan, dan pertolongan yang tepat dalam kasus ini adalah Basic Life Support (BLS), dalam bahasa Indonesia BLS dikenal dengan Bantuan Hidup Dasar (BHD). Sesuai dengan data dari AHA 2015 korban Out of Heart Cardiac Arrest (OHCA) dapat terselamatkan setelah mendapatkan Resusitasi Jantung Paru (RJP) oleh bystander (orang awam) sebesar 40,1\%. Hal ini disebabkan karena kejadian dari Out Hospital Cardiac Arrest (OHCA) sekitar $80 \%$ terjadi di rumah dan di tempat umum sekitar $20 \%$, sehingga sangatlah penting peran dari bystander dalam memberikan RJP secepat mungkin terhadap korban OHCA, (Perkins, dkk, 2015).

Basic Life Support atau dalam bahasa Indonesia dikenal dengan Bantuan Hidup Dasar (BHD) adalah segala usaha yang dilakukan untuk dapat mempertahankan kehidupan pada saat seseorang mengalami kondisi kegawatdaruratan yang mengancam jiwa (AHA, 2015). BHD atau dikenal dengan Resusitasi Jantung Paru (RJP) yaitu sekumpulan usaha atau intervensi yang dilakukan dengan tujuan untuk mengembalikan dan mempertahankan fungsi organ penting pada korban dengan henti jantung dan henti nafas. Intervensi ini terdiri dari pemberian kompresi dada dan bantuan nafas. (Ngirarung, Mulyadi, \& Malara, 2017)

Menurut AHA Guidelines tahun 2015, BHD dilakukan pada orang dengan keadaan kegawatdaruratan seperti henti nafas (respiratory arrest), dan henti jantung (cardiac arrest). Penyebab utama kematian diluar rumah sakit dan di rumah sakit adalah serangan jantung mendadak. Hasil dari pengamatan penelitian di Eropa yaitu Resusitasi Jantung Paru (RJP) dapat meningkatkan kelangsungan hidup di rumah sakit (Mauri R, dkk, 2015). Sedangkan di Indonesia, prevalensi atau data untuk penderita cardiac arrest setiap tahunnya belum jelas, namun diperkirakan warga Indonesia yang mengalami cardiac arrest sekitar 10.000 (Riskesdas, 2013).

Sehingga, sangat diperlukan untuk mengajarkan mengenai keterampilan BHD pada siapa saja, terutama orang dewasa. Dalam hal ini artinya kita semua membutuhkan peningkatan jumlah bystander BHD di lingkungan masyarakat. Pemberian simulasi tindakan Resusitasi Jantung Paru (RJP) kepada remaja dikalangan Karang Taruna merupakan hal yang sangat penting untuk dilakukan dan bermanfaat agar dapat meningkatkan jumlah orang yang terlatih dalam melakukan BHD sehingga dapat menjadi bystander di lingkungannya masing-masing.

Selain itu proses simulasi membutuhkan pengetahuan dan motivasi dari setiap pelajar. Dapat kita ketahui bahwa proses belajar mengajar dapat berhasil jika didukung dan dipengaruhi oleh motivasi belajar dan motivasi untuk melakukan BHD. Motivasi belajar dapat memberikan pengaruh positif yang signifikan terhadap proses belajar, yang berarti jika motivasi belajar meningkat, maka cenderung meningkatkan kompetensinya (Bakar 2014 dalam, Silvana \& Sumbawati, 2017). Keterampilan itu sendiri merupakan sebuah hasil dari output suatu pelatihan. Diharapkan skill atau keterampilan seseorang akan meningkat setelah dilakukan pelatihan berupa simulasi BHD. Skill atau keterampilan merupakan suatu kemampuan untuk menuangkan pengetahuan ke dalam praktik sehingga tercapai hasil yang diinginkan, (Suprapto T, 2009).

Hasil studi pendahuluan pada 25 remaja Karang Taruna RW 06 Kelurahan Krukut, Depok didapatkan data bahwa 3 orang $(12 \%)$ pernah mengikuti pelatihan mengenai BHD dan 22 orang $(88 \%)$ belum pernah, 7 orang $(28 \%)$ mengatakan tidak pernah ada yang 
meninggal tiba-tiba di lingkungannya dan 18 orang (72\%) mengatakan pernah ada yang meninggal tiba-tiba di lingkungannya, 6 orang $(24 \%)$ keluarganya memiliki penyakit jantung dan 19 orang (76\%) keluarganya tidak memiliki penyakit jantung.

Berdasarkan uraian di atas serta beberapa penelitian sebelumnya mengenai Bantuan Hidup Dasar (BHD) dalam melakukan Resusitasi Jantung Paru (RJP), maka peneliti tertarik untuk melakukan penelitian pengaruh simulasi pelatihan Bantuan Hidup Dasar (BHD) Terhadap Motivasi dan Skill Resusitasi Jantung Paru (RJP) Pada Karang Taruna RW 06 Kampung Utan Kelurahan Krukut Depok.

\section{METODE PENELITIAN}

Penelitian ini menggunakan metode quasi experiment Pre-post test without control group yaitu penelitian yang menguji coba suatu perlakuan tanpa kelompok pembanding, namun dengan time series yaitu penelitian eksperimen dengan mengukur pengaruh dari intervensi yang diberikan berdasarkan perjalanan waktu. Penelitian ini dilakukan untuk menganalisis pengaruh antara simulasi BHD dengan motivasi dan skill RJP Karang Taruna RW 06 Kampung Utan. Kelompok subyek diobservasi sebelum dan sesudah dilakukan intervensi. Penelitian dilakukukan di Karang Taruna RW 06 Kampung Utan Krukut Depok, pada bulan Mei hingga Juni 2019.

Populasi pada penelitian ini adalah seluruh Karang Taruna RW 06 Kampung Utan Krukut yang berjumlah 60 orang. Teknik pengambilan sampel yang digunakan adalah Consecutive sampling yaitu cara pemilihan sampel yang dilakukan dengan memilih siapapun yang ditemui dan memenuhi kriteria hingga jumlah sampel terpenuhi (Dharma, 2015). Sampel berdasarkan perhitungan peneliti pada penelitian ini berjumlah 23 orang, untuk menghindari adanya dropout maka peneliti menambahkan $10 \%$ sehingga sampel menjadi 26 .

Penelitian ini menggunakan insrumen berupa lembar observasi RJP saat responden mensimulasikan RJP dengan manekin atau phantom, dan untuk mengukur tingkat motivasi dalam menolong atau melakukan RJP, peneliti menggunakan kuesioner. Sebelumnya kuesioner diberikan kepada responden peneliti melakukan uji validitas dengan 22 pertanyaan menggunakan uji skewness, yang menghasilkan 17 pertanyaan valid. Pertanyaan tersebut menggunakan skala linkert dengan bobot skor pertanyaan favorable dan unfavorable adalah Selalu $(\mathrm{SL})=4$, Sering $(S)=3$, Kadang-kadang $(K)=2$, dan Tidak Pernah $(\mathrm{TP})=1$. Pertanyaan-pertanyaan ini disusun berdasarkan teori-teori yang berhubungan dengan motivasi dan beberapa contoh kasus yang dapat mempengaruhi motivasi. Karakteristik responden yang digunakan pada penelitian ini adalah usia, jenis kelamin, pendidikan, dan pengetahuan.

\section{HASIL DAN PEMBAHASAN}

Tabel 1. Distribusi Rata-rata Usia Pada Karang Taruna RW 06 Kelurahan Krukut, Depok Tahun $2019(n=23)$

\begin{tabular}{lcccc}
\hline Karakteristik & Mean & SD & Min & Max \\
\hline Usia & 17,48 & 2,678 & 13 & 23 \\
\hline
\end{tabular}

Berdasarkan tabel 1 data yang diperoleh menunjukan bahwa distribusi responden berdasarkan usia memiliki rata-rata 17,48 tahun. Hal ini sesuai dengan penelitian yang dilakukan oleh Sentana (2018) yang berjudul "Efektifitas Video CPR Terhadap Kemampuan Masyarakat Awam Dalam Melakukan CPR di Desa Sembung Kecamatan Narmada" bahwa kelompok umur responden yang paling banyak pada kelompok kontrol maupun perlakuan merupakan kelompok remaja hingga remaja akhir yaitu 17 tahun sampai dengan 25 tahun. Menurut Thoyyibah (2014) pada saat remaja akan mudah termotivasi dan mudah 
menangkap pelajaran karena pada saat itu tahap perkembangan ukuran tubuh, massa otot, proses berpikir, dan kemampuan bereproduksi, berkembang dengan pesat sehingga remaja diharapkan dapat menjadi bystander di lingkungannya.

Tabel 2. Distribusi Frekuensi Bedasarkan Jenis Kelamin dan Pendidikan Pada Karang Taruna RW 06 Kelurahan Krukut, Depok Tahun 2019 (n= 23)

\begin{tabular}{lcc}
\hline \multicolumn{1}{c}{ Variabel } & $\begin{array}{c}\text { Frekuensi } \\
(\mathbf{~ n ~})\end{array}$ & $\begin{array}{c}\text { Presentase } \\
\mathbf{( \% )}\end{array}$ \\
\hline \multicolumn{1}{c}{ Jenis Kelamin } & & \\
Laki-laki & 11 & 47,8 \\
Perempuan & 12 & 52,2 \\
Total & $\mathbf{2 3}$ & $\mathbf{1 0 0}$ \\
\hline$\quad$ Pendidikan & & \\
SMP-SMA & 16 & 69,6 \\
Perguruan Tinggi & 7 & 30,4 \\
Total & $\mathbf{2 3}$ & $\mathbf{1 0 0}$ \\
\hline
\end{tabular}

Berdasarkan tabel 2 data yang diperoleh menunjukkan bahwa dari 23 responden jumlah responden terbanyak adalah perempuan yaitu sebanyak 12 siswa (52,2\%). Pada tabel hasil penelitian menunjukan bahwa sebagian besar responden pada penelitian ini berpendidikan SMP hingga SMA sebanyak 16 orang $(69,6 \%)$.

Tabel 3 Distribusi Rata-rata Pengetahuan BHD Pada Karang Taruna RW 06 Kelurahan Krukut, Depok Tahun 2019 ( $\mathrm{n}=23)$

\begin{tabular}{ccccccc}
\hline Variabel & n & Mean & $\begin{array}{c}\text { Skor } \\
\text { Persentase (\%) }\end{array}$ & SD & Min-Max & $\begin{array}{c}\text { 95\% CI } \\
\text { (Low-Up) }\end{array}$ \\
\hline $\begin{array}{c}\text { Pre-test } \\
\text { Penegetahuan BHD }\end{array}$ & 23 & 10.13 & 50.65 & 2.282 & $5-17$ & $9.14-11.12$ \\
\cline { 3 - 6 } $\begin{array}{c}\text { Post-test } \\
\text { Penegetahuan BHD }\end{array}$ & 17.04 & 85.2 & 1.718 & $14-20$ & $16.30-17.79$ \\
\hline
\end{tabular}

Pada tabel 3 di atas pengetahuan responden mengenai BHD pada saat pre-test memiliki rata-rata (mean) 10.13 setelah diberikan intervensi, menunjukkan kenaikan menjadi 17,04.

Tabel 4. Distribusi Rata-rata Motivasi Melakukan BHD Pada Karang Taruna RW 06 Kelurahan Krukut, Depok Tahun 2019 (n = 23)

\begin{tabular}{|c|c|c|c|c|}
\hline Variabel & $\mathbf{n}$ & Mean & SD & Min-Max \\
\hline $\begin{array}{l}\text { Pre-test motivasi } \\
\text { melakukan BHD }\end{array}$ & \multirow{4}{*}{23} & 14.39 & 2.919 & $8-18$ \\
\hline $\begin{array}{l}\text { Post-test motivasi } \\
\text { melakukan BHD }\end{array}$ & & 18.04 & 0.976 & $16-20$ \\
\hline $\begin{array}{c}\text { Pre-test motivasi } \\
\text { belajar BHD }\end{array}$ & & 36.26 & 6.390 & $27-48$ \\
\hline $\begin{array}{l}\text { Post-test motivasi } \\
\text { belajar BHD }\end{array}$ & & 40.65 & 4.579 & $34-48$ \\
\hline
\end{tabular}


Tabel 4 diatas menunjukkan bahwa motivasi untuk melakukan BHD responden pada saat pre-test memiliki rata-rata (mean) 14,39 meningkat pada saat post-test menjadi 18,04. Kemudian, selain motivasi melakukan BHD peneliti juga melakukan motivasi belajar BHD, menghasilkan nilai mean 36,26 untuk pre-test dan 40,65 ketika post-test.

Hasil penelitian yang dilakukan oleh Anugrahwati (2017) mengenai faktor-faktor yang berpengaruh terhadap motivasi belajar adalah cita-cita, kemampuan belajar, perlunya komunikasi yang baik antara pengajar dengan yang diajarkan, feedback, dan kemauan atau minat,. Semua hal tersebut merupakan beberapa faktor dari faktor-faktor lainnya yang mungkin belum diteliti oleh peneliti.

Tabel 5 Distribusi Rata-rata Skill RJP Pada Karang Taruna RW 06 Kelurahan Krukut, Depok Tahun $2019(n=23)$

\begin{tabular}{|c|c|c|c|c|c|}
\hline Variabel & $\mathbf{n}$ & Mean & SD & Min-Max & $\begin{array}{c}95 \% \text { CI } \\
\text { (Low-Up) }\end{array}$ \\
\hline Skill RJP sebelum intervensi & \multirow{4}{*}{23} & 1.65 & 3.700 & $0-18$ & $0.05-3.25$ \\
\hline Skill RJP Observasi 1 & & 18.39 & 3.115 & $15-29$ & $17.04-19.74$ \\
\hline Skill RJP Observasi 2 & & 26.61 & 2.808 & $23-33$ & 25.39-27.82 \\
\hline Skill RJP Observasi 3 & & 29.96 & 2.708 & $25-34$ & $29.06-30.85$ \\
\hline
\end{tabular}

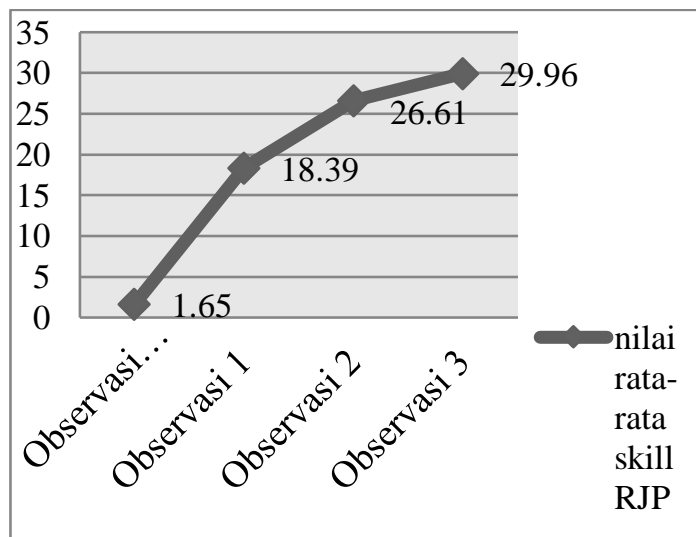

Grafik 1. Observasi Sebelum Pelatihan Hingga Observasi ke-3

Observasi skill RJP ini dilakukan selama 3 kali dalam selang waktu 1 minggu setiap observasi. Grafik tersebut menunjukan terdapat kenaikan nilai rata-rata skill RJP selama observasi. Namun kenaikan tertinggi pada saat sebelum dilakukan intervensi dan sesudah dilakukan intervensi pada observasi pertama sebesar 16,74.

Tabel 6. Analisis Usia Responden Terhadap Motivasi Melakukan BHD Pada Karang Taruna RW 06 Kelurahan Krukut, Depok Tahun 2019 (n = 23)

\begin{tabular}{ccc}
\hline Variabel & $\begin{array}{c}\text { Person Correlation } \\
(\mathbf{R})\end{array}$ & P value \\
\hline Usia & 0,479 & 0,021 \\
\hline
\end{tabular}

Berdasarkan hasil analisis data pada tabel 6 didapatkan hasil p value 0,001 dan nilai $\mathrm{r}=0,479$. Nilai $\mathrm{p}$ value $<0,05$ hal ini menunjukkan bahwa usia mempengaruhi motivasi seseorang.Hasil peneliatan ini sejalan dengan penelitian yang dilakukan oleh Anugrahwati 
(2017) yang berjudul “Faktor-faktor yang Berperan Terhadap Motivasi Belajar Mahasiswa di Akademi Keperawatan Manggala Husada Jakarta" yaitu dari 123 responden yang tidak memiliki motivasi belajar pada rentang usia 15-20 tahun sebanyak 21 orang $(17,1 \%)$, sedangkan yang memiliki motivasi sebanyak 102 oranng (82,9\%). Kemudian pada rentang usia 21-25 tahun 3 orang (15\%) tidak memiliki motivasi, dan 17 orang (85\%) memiliki motivasi. Hasil $\mathrm{p}$ value 0,796 maka dapat disimpulkan bahwa tidak ada hubungan yang signifikan antara usia dengan motivasi seseorang.Peneliti berasumsi bahwa motivasi tidak didasarkan pada usia seseorang namun bergantung pada faktor internal berupa minat, keinginan atau kemauan, dan faktor eksternal berupa lingkungan, maupun teman sebaya. Motivasi sifatnnya tertutup, yaitu hanya dapat dirasakan oleh diri sendiri.

Tabel 7. Analisis Jenis Kelamin Responden Terhadap Motivasi Melakukan BHD Pada Karang Taruna RW 06 Kelurahan Krukut, Depok Tahun 2019 (n = 23)

\begin{tabular}{|c|c|c|c|c|c|c|}
\hline Jenis kelamin & $\mathbf{n}$ & Mean & SD & $\mathrm{SE}$ & p-value & $\begin{array}{c}\text { 95\% CI (Low- } \\
\text { Up) }\end{array}$ \\
\hline Laki-laki & 11 & 17.82 & .874 & .263 & \multirow{2}{*}{0.300} & $-1.277-0.413$ \\
\hline Perempuan & 12 & 18.25 & 1.055 & .305 & & $-1.277-0.406$ \\
\hline
\end{tabular}

Berdasarkan hasil analisis data pada tabel 7 diatas didapatkan nilai $\mathrm{p}$ value sebesar 0.300, karena nilai $\mathrm{p}>0,05$ maka jenis kelamin tidak mempengaruhi motivasi baik jenis kelamin laki-laki maupun perempuan.

Hal ini sejalan dengan penelitian yang dilakukan oleh (Ngirarung, Mulyadi, \& Malara, 2017) bahwa dari 33 responden jumlah responden terbanyak adalah perempuan yaitu sebanyak 21 siswa (63,6\%). Karakteristik antara jenis kelamin dengan motivasi tidak memiliki hubungan atau pengaruh yang signifikan terhadap tingkat motivasi.

Asumsi peneliti berdasarkan hasil yang didapat adalah perbedaan besar perbandingan antara laki-laki dan perempuan harus seimbang, sehingga data yang dihasilkan valid. Selain itu peneliti berpendapat bahwa motivasi tidak didasarkan pada jenis kelamin, namun motivasi merupakan dorongan yang ada pada diri setiap orang dalam berperilaku untuk mencapai tujuan yang diinginkan. Seseorang akan memiliki motivasi yang tinggi jika adanya kebutuhan, dorongan, dan keinginan untuk melakukan suatu hal. Menurut (Saam Z \& Wahyuni S, 2012) dilihat dari kekuatannya motivasi intrinsik lebih baik dibanding ekstrinsik, hal ini disebabkan karena seseorang yang menjalankan sesuatu dengan senang dan memiliki minat tertentu maka cenderung meningkat motivasinya.

Tabel 8. Analisis Tingkat Pendidikan Responden Terhadap Motivasi Melakukan BHD Pada Karang Taruna RW 06 Kelurahan Krukut, Depok Tahun 2019 (n = 23)

\begin{tabular}{ccccccc}
\hline Pendidikan & $\mathbf{n}$ & Mean & SD & SE & p-value & $\begin{array}{c}\text { 95\% CI } \\
\text { (Low-Up) }\end{array}$ \\
\hline Rendah & 16 & 17.81 & 0.981 & 0.245 & \multirow{2}{*}{0.086} & $\frac{-1.635-0.117}{-1.584-0.066}$ \\
\hline Tinggi & 7 & 18.57 & 0.787 & 0.297 & & \\
\hline
\end{tabular}

Hasil analisis data pada tabel 8 diatas, didapatkan nilai $p$ value uji statistik pendidikan terhadap motivasi adalah 0,086 , karena nilai $\mathrm{p}$ value $>0,05$ maka hasil yang didapatkan adalah pendidikan tidak memberikan pengaruh yang berarti terhadap motivasi untuk melakukan Bantuan Hidup Dasar (BHD).

Menurut asumsi peneliti, pendidikan bukan faktor yang mendominasi terhadap motivasi seseorang. Namun motivasi yang paling mempengaruhi seseorang untuk bertindak adalah yang berasal dari kemauan diri sendiri, meskipun pendidikan juga 
memiliki peran tersendiri. Nyatanya motivasi yang berasal dari internal lebih baik dari pada motivasi eksternal, meskipun motivasi eksternal dapat memicu minat dan kemauan pada diri seseorang.

Tabel 9. Analisis Pengetahuan Responden Terhadap Motivasi Melakukan BHD Pada Karang Taruna RW 06 Kelurahan Krukut, Depok Tahun 2019 (n = 23)

\begin{tabular}{ccc}
\hline Variabel & Pearson Correlation (R) & p-Value \\
\hline Pengetahuan & 0.761 & 0.000 \\
\hline
\end{tabular}

Berdasarkan hasil analisis data pada tabel 9, didapatkan hasil $\mathrm{p}$ value sebesar 0,000 dan nilai $\mathrm{r}=0,761$. Nilai $\mathrm{p}$ value $<0,05$ hal ini menunjukkan bahwa pengetahuan mempengaruhi motivasi seseorang. Jika dilihat dari nilai $r$ maka dapat disimpulkan bahwa antara pengetahuan dengan motivasi bernilai positif, yaitu semakin tinggi pengetahuan responden maka semakin tinggi motivasi untuk melakukan BHD.

Hasil penelitian yang dilakukan oleh Astutik (2017) tentang "Hubungan Pengetahuan Bantuan Hidup Dasar (BHD) dengan Motivasi pada Polisi Lalu Lintas Dalam Memberikan Pertolongan Pada Korban Kecelakaan Lalu Lintas di Kota Magetan" didapatkan hasil nilai p value 0,005 artinya a $<0,05$ sehingga terdapat hubungan antara pengetahuan BHD dengan motivasi. Semakin tinggi pengetahuan maka akan semakin tinggi pula motivasi yang dimiliki.

Menurut Uno (2014), dalam Silvana \& Sumbawati (2017) setiap orang memiliki dorongan internal dan eksternal yang berbeda dalam melakukan sesuatu sehingga tidak dapat disamaratakan antara satu dengan yang lainnya. Lestari (2015) mengatakan bahwa pengetahuan merupakan hasil yang diperoleh dari pancainera.

\section{Tabel 10. Analisis Responden Berdasarkan Usia Terhadap Skill RJP Pada Karang Taruna RW 06 Kelurahan Krukut, Depok Tahun 2019 (n= 23)}

\begin{tabular}{ccc}
\hline Variabel & $\begin{array}{c}\text { Person Correlation } \\
(\mathbf{R})\end{array}$ & $\begin{array}{c}\mathbf{P} \\
\text { Value }\end{array}$ \\
\hline Usia & 0,025 & 0,911 \\
\hline
\end{tabular}

Berdasarkan hasil analisis data pada tabel 10 didapatkan hasil $p$ value 0,911 dan nilai $\mathrm{r}=0,025$. Nilai $\mathrm{p}$ value $>0,05$ hal ini menunjukkan bahwa usia tidak mempengaruhi skill Resusitasi Jantung Paru (RJP) seseorang.

Menurut penelitian Kaweenuttayanon (2017) dengan judul “Defining the Optimal Age for Basic Life Support and Cardiac Training in Thai Adolescents" mengatakan bahwa perbedaan skor (post-test dikurang pre-test) meningkat dengan signifikan pada semua umur yang dalam penelitian tersebut pada umur 13 sampai 18 tahun. Selain itu menurut penelitian di England, menemukan bahwa 10 sampai 12 tahun pelajar memiliki kemampuan untuk belajar mengenai teori BHD dengan pelatihan, sehingga meningkatkan nilai post-test setelah pelatihan atau pembelajaran (Connolly, 2007 dalam Kaweenuttayanon, 2017).

Maka dari itu peneliti mengadakan pelatihan pada Karang Taruna yang didalamnya didominasi oleh remaja yang usianya sudah cukup mampu untuk menerima pembelajaran mengenai BHD, disertai dengan kekuatan yang optimal untuk melakukan tindakan RJP. Hasil dari penelitian dan berdasarkan literatur yang didapatkan oleh peneliti, maka peneliti berasumsi bahwa usia yang tepat untuk diajarkan BHD adalah usia remaja hingga dewasa muda yaitu 13 sampai 25 tahun, karena tahap perkembangan remaja hingga dewasa awal 
adalah tahap yang paling optimal dalam segi konsentrasi, kekuatan, dan kemampuan praktikal.

Tabel 11. Analisis Responden Berdasarkan Jenis Kelamin Terhadap Skill RJP Pada Karang Taruna RW 06 Kelurahan Krukut, Depok Tahun 2019 (n= 23)

\begin{tabular}{lcccccc}
\hline Jenis kelamin & $\mathbf{n}$ & Mean & SD & SE & p-value & $\begin{array}{c}\text { 95\% CI (Low- } \\
\text { Up) }\end{array}$ \\
\hline Laki-laki & 11 & 30.55 & 2.583 & 0.779 & \multirow{2}{*}{0.789} & $\frac{-1.970-2.561}{-1.968-2.559}$ \\
\hline Perempuan & 12 & 30.25 & 2.633 & 0.760 & & \\
\hline
\end{tabular}

Hasil analisis data pada tabel 11, didapatkan rata-rata (mean) jenis kelamin laki-laki dengan skill adalah 30,55 dan perempuan 30,25. Dari hasil analisis data diatas didapatkan nilai $p$ value sebesar 0.789 karena nilai $p>0,05$ maka jenis kelamin tidak mempengaruhi skill melakukan RJP baik jenis kelamin laki-laki maupun perempuan.

Menurut penelitian yang dilakukan Yumniyati (2016) nilai $\mathrm{F}$ hitung < F tabel yaitu $0,146<3,904$ yang artinya tidak ada pengaruh antara jenis kelamin dalam kemampuan berpikir kreatif, serta kemampuan tehnikal. Pada umumnya saat ini perempuan dan lakilaki diberikan kesempatan yang sama untuk memperoleh pendidikan maupun pelatihanpelatihan keterampilan. Hal ini bertolakbelakang dengan hasil penelitian yang dilakukan oleh peneliti. Meskipun nilai rata-rata perempuan lebih rendah dari laki-laki namun hasil $\mathrm{p}$ value menunjukan tidak adanya hubungan. Peneliti berasumsi bahwa perempuan lebih mampu berkonsentrasi ketika diadakan pelatihan, sehingga pengetahuan perempuan lebih baik dibandingkan laki-laki dan pengetahuan itu mempengaruhi skill dalam melakukan tindakan RJP.

Pernyataan tersebut sejalan dengan Yunitasai (2018) dengan judul "Pengaruh Pendidikan Kesehatan dan Simulasi Terhadap Pengetahuan Dan Keterampilan Pertolongan Pertama Pada Siswa Yang Mengalami Sinkop Di SMA 7 Manado" yang mengatakan bahwa seseorang yang memiliki pengetahuan yang baik memiliki skill yang lebih baik dibanding seseorang yang menolong tanpa pengetahuan yang baik, serta melalui praktik.

Masykur (2008) dalam Yumniyati (2016) menjelaskan bahwa pusat memori (hipotalamus) pada otak perempuan lebih besar daripada laki-laki. Sehingga perempuan memiliki ingatan yang lebih kuat dibanding laki-laki. Dalam penelitian ini perempuan lebih mampu mengingat langkah-langkah dalam melakukan RJP, meskipun dalam kompresi dada laki-laki lebih optimal saat melakukan kompresi dada dibanding perempuan karena memiliki kekuatan otot yang lebih kuat. Hal ini sejalan dengan penelitian Kenney, Wilmore, \& Costil (2015) bahwa kekuatan otot ekstremitas atas perempuan 40\%-60\% lebih lemah daripada laki-laki. Berdasarkan hasil penelitian Krammel, dkk (2018) yang berjudul "Gender and Age Spesific Aspecs of Awarness and Knowledge in Basic Life Support" menyatakan bahwa dalam pengetahuan dan kesadaran peserta tentang BHD perempuan lebih memiliki pengetahuan yang baik dibanding laki-laki, hanya dalam keterampilan RJP laki-laki lebih baik dibanding perempuan.

Tabel 12 . Analisis Responden Berdasarkan Tingkat Pendidikan Terhadap Skill RJP Pada Karang Taruna RW 06 Kelurahan Krukut, Depok Tahun 2019 (n = 23)

\begin{tabular}{|c|c|c|c|c|c|c|}
\hline Pendidikan & $\mathrm{n}$ & Mean & SD & SE & p-value & $\begin{array}{c}95 \% \text { CI } \\
\text { (Low-Up) }\end{array}$ \\
\hline SMP-SMA & 16 & 30.25 & 2.620 & 0.655 & \multirow{2}{*}{0.698} & $-2.919-1.990$ \\
\hline Perguruan Tinggi & 7 & 30.71 & 2.563 & 0.969 & & $-3.018-2.090$ \\
\hline
\end{tabular}


Hasil analisis data pada tabel 12 diatas, didapatkan nilai $\mathrm{p}$ value uji statistik pendidikan terhadap skill adalah 0,698. Nilai rata-rata (mean) untuk yang berpendidikan rendah adalah 30,25, sedangkan nilai rata-rata (mean) yang berpendidikan tinggi sebesar 30,71 . Karena nilai $\mathrm{p}$ value $>0,05$ maka hasil yang didapatkan adalah pendidikan tidak memberikan pengaruh terhadap skill untuk melakukan RJP.

Menurut Maulana (2007) yang dikutip dari penelitian yang dilakukan oleh Mais (2015) mengatakan bahwa seseorang yang memiliki pengetahuan yang baik, diserap melalui pancaindera, untuk itu semakin banyak pancaindera yang digunakan, maka pemahaman dan pengetahuannya semakin baik pula sehingga perhatiannya akan terfokuskan.

Peneliti berasumsi bahwa dalam penelitian ini responden masih banyak yang sedang melakukan pendidikan dari SMP hingga Perguruan Tinggi, sehingga berdasarkan hasil observasi responden yang sedang menjalani jenjang pendidikan SMP-SMA dengan perguruan tinggi tidak ada perbedaan yang signifikan. Kemampuan atau skill dapat ditingkatkan melalui latihan secara rutin, menambah pengetahuan secara otodidak, dan tehnik yang benar, meskipun dengan pendidikan yang dinilai rendah.

\section{Tabel 13 . Analisis Responden Berdasarkan Pengetahuan Terhadap Skill RJP Pada Karang Taruna RW 06 Kelurahan Krukut, Depok Tahun 2019 (n = 23)}

\begin{tabular}{ccc}
\hline Variabel & Pearson Correlation (R) & p-Value \\
\hline Pengetahuan & 0.866 & 0.000 \\
\hline
\end{tabular}

Berdasarkan hasil analisis data pada tabel 13, didapatkan hasil $p$ value sebesar 0.000 dan nilai $\mathrm{r}=0,866$. Nilai $\mathrm{p}$ value $<0,05$ hal ini menunjukkan bahwa pengetahuan mempengaruhi skill RJP seseorang. Hasil penelitian ini sejalan dengan penelitian yang dilakukan oleh Ardiansyah (2019) dengan judul "Faktor Penentu Kualitas Kompresi Resusitasi Jantung Paru Oleh Perawat" dengan p value $0,001(\alpha<0,05)$ yang artinya terdapat hubungan yang signifikan antara pengetahuan BHD dengan skill perawat dalam melakukan tindakan RJP. Pengetahuan mengenai RJP dapat ditingkatkan melalui pelatihan rutin supaya pengetahuan selalu bertambah.

Berdasarkan uraian diatas, maka peneliti berasumsi bahwa seseorang yang memiliki pengetahuan yang baik maka akan cenderung mampu memberikan BHD dengan baik, namun sebaliknya jika memiliki pengetahuan yang rendah maka kemampuan dalam menangani tindakan BHD akan cenderung kurang terampil.

Tabel 14 . Analisis Motivasi Responden Sebelum (Pretest) dan Sesudah (Posttest) Pelatihan Resusitasi Jantung Paru (RJP) Pada Karang Taruna RW 06 Kelurahan Krukut, Depok Tahun $2019(n=23)$

\begin{tabular}{|c|c|c|c|c|c|}
\hline Variabel & $\mathbf{n}$ & Mean & Selisih & SD & SE \\
\hline Motivasi melakukan BHD Pre-test & \multirow{2}{*}{23} & 14.39 & & 2.919 & 0.609 \\
\hline Motivasi melakukan BHD Post-test & & 18.04 & & 0.976 & 0.204 \\
\hline
\end{tabular}

Hasil analisis data pada tabel 14 didapatkan uji statistik untuk rata-rata motivasi pada saat pretest adalah 14,39 dan rata-rata post-test sebesar 18,04. Selisih rata-rata pretest dan posttest sebesar 3,65. Didapatkan nilai $p$ value motivasi sebelum dan sesudah intervensi 0,000 . Menurut tabel tersebut maka nilai $\mathrm{p}<0,05$ menunjukkan bahwa terdapat pengaruh yang signifikan antara simulasi Bantuan Hidup Dasar (BHD) terhadap motivasi melakukan BHD. 
Hasil penelitian tersebut sejalan dengan penelitian (Ngirarung dkk., 2017) yang berjudul "Pengaruh Simulasi Tindakan Resusitasi Jantung Paru (RJP) Terhadap Tingkat Motivasi Siswa Menolong Korban Henti Jantung Di SMA Negeri 9 Binsus Manado" hasil dari uji statistik Wilcoxon menunjukan nilai $p$ value $0,000(\alpha<0,05)$ maka Ho ditolak artinya terdapat pengaruh pelatihan terhadap tingkat motivasi.

Asumsi peneliti adalah bahwa motivasi seseorang dipengaruhi oleh berbagai faktor. Faktor intrinsik dan faktor ekstrinsik merupakan faktor-faktor yang mempengaruhi motivasi seseorang. Faktor intrinsik yaitu kesehatan, perhatian, minat, dan bakat. Sedangkan yang termasuk ke dalam faktor ekstrinsik adalah metode mengajar, alat pelajaran, dan kondisi lingkungan. Motivasi dalam belajar memberikan pengaruh yang baik terhadap proses belajar, yang artinya jika motivasi belajar meningkat, maka akan cenderung meningkatkan kompetensinya (Bakar 2014 dalam,Silvana \& Sumbawati, 2017).

\section{Tabel 15 . Analisis Skill RJP Responden Sebelum (Pretest) dan Sesudah (Posttest) diberikan Pelatihan BHD Pada Karang Taruna RW 06 Kelurahan Krukut, Depok Tahun $2019(n=23)$}

\begin{tabular}{ccccccc}
\hline Variabel & n & Mean & Selisih & Median & Min-Max & p-Value \\
\cline { 1 - 4 } & \multirow{2}{*}{23} & 1.65 & \multirow{2}{*}{28.74} & 17.00 & $0-18$ & \multirow{2}{*}{0.000} \\
\cline { 1 - 4 } & & 30.39 & & 31.00 & $25-34$ & \\
\hline Skill Pre-test & & & & &
\end{tabular}

Berdasarkan tabel 15 diatas, analisis data didapatkan dari hasil uji statistik untuk rata-rata (mean) skill sebelum diberikan intervensi atau pre-test adalah 1,65 namun setelah dilakukan intervensi berupa pelatihan RJP nilai mean menjadi 30,39. hasil analisis bivariat dengan menggunakan Uji Wilcoxon Sign Test diperoleh nilai $\mathrm{p}$ value 0,000, nilai $\mathrm{p}$ value < 0,005 hal ini menunjukan bahwa terdapat pengaruh yang signifikan dalam pemberian simulasi BHD terhadap skill RJP yang dibuktikan dengan perbedaan nilai rata-rata skill sebelum dan sesudah pelatihan. Selisih rata-rata skill RJP sebelum dan sesudah intervensi sebesar 28,74 .

Hal tersebut sejalan dengan hasil penelitian Endiyono,\& Prasetyo (2018) yang berjudul "Pengaruh Latihan Basic Life Support Terhadap Pengetahuan dan Keterampilan Tim Muhammadiyah Disaster Management (MDMC) Banyumas" didapatkan nilai $\mathrm{p}$ value sebesar 0,0001 $(a<0,05)$ yang artinya terdapat pengaruh pelatihan Basic Life Support terhadap keterampilan TIM SAR MDMC Banyumas mengenai BLS. Peningkatan ini sebesar 1.47 point yaitu dari 2,83 menjadi 4,7 point.

Hasil penelitian ini juga didukung oleh Widyarani (2018) dalam penelitiannya dengan judul "Analisis Pengaruh Pelatihan Resusitasi Jantung Paru (RJP) Dewasa Terhadap Retensi Pengetahuan Dan Ketrampilan RJP Pada Mahasiswa Keperawatan di Yogyakarta" didapatkan hasil bahwa rata-rata kemampuan skill RJP sebelum dilakukan pelatihan yaitu 35,55 , sedangkan setelah dilakukan pelatihan rata-rata kemampuannya menjadi 91,80 . Berdasarkan hasil uji T-Dependen hasil $p$ value sebesar $0.000(\alpha<0,05)$ yang artinya terdapat pengaruh yang signifikan antara kemampuan sebelum dan sesudah diberikan pelatihan mengenai RJP.

Berdasarkan hasil dari penelitian ini, keterampilan responden dalam melakukan RJP dinilai dengan indikator rujukan AHA (2015) yaitu 1) mengidentifikasi korban henti jantung dengan 3A, mengecek respon korban, call for help, pengaktifan Emergency Medicall Service (EMS) ; 2) membuka jalan nafas, look, listen and feel serta cek nadi ; 3) high quality CPR, yaitu kedalaman kompresi dada $(5-6 \mathrm{~cm})$, recoil, meminimalkan interupsi, rasio kompresi 30:2 pernapasan, kecepatan kompresi dada minimal 100-120 kali/menit.

Dalam melakukan tindakan tersebut, rata-rata responden dalam melakukan RJP menunjukan kurang mampu untuk melakukan cara membuka jalan nafas, lupa 
membedakan antara tindakan untuk korban dengan fraktur servikal yaitu jaw thrust dan yang tidak mengalami fraktur servikal yaitu head thin chin lips. Selain itu dalam memberikan ventilasi rata-rata responden lupa untuk memberikan barrier ke phantom, padahal memberikan barrier sangat penting dilakukan untuk mencegah penularan penyakit dari korban ke penolong, maupun penolong ke korban.

Pada saat melakukan kompresi dada ketika observasi pertama responden kurang mampu melakukan kompresi secara tepat, hal ini dikarenakan teknik dan posisi yang dilakukan kurang tepat. Namun setelah observasi ke 2 dan 3 responden menunjukan perubahan dalam melakukan RJP sehingga mencapai kedalaman dan kecepatan yang sesuai dengan SOP. Menurut peneliti, teknik atau posisi untuk melakukan RJP sangat mempengaruhi dalam mencapai high quality $C P R$.

\section{KESIMPULAN}

Hasil penelitian menunjukkan bahwa metode simulasi pelatihan BHD dapat memberikan pengaruh yang cukup signifikan terhadap peningkatan motivasi melakukan BHD serta skill dalam melakukan RJP pada Karang Taruna RW 06 Kampung Utan Krukut.

\section{SARAN}

Penelitian selanjutnya dapat dilakukan simulasi pelatihan RJP dengan menggunakan kelompok kontrol agar dapat mengukur efektifitas metode yang digunakan

\section{DAFTAR PUSTAKA}

American Heart Association. (2015). Pembaharuan Pedoman AHA 2015 untuk CPR dan ECC. Dikutip dari http:// eccguidlines.heart.org pada tanggal 30 Januari 2019

Anugrahwati, Ria., Hartati, Suryani. (2017). Faktor-Faktor Yang Berperan Terhadap Motivasi Belajar Mahasiswa di Akademi Keperawatan Manggala Husada Jakarta. Volume 8 (2)

Ardiansyah, Fakrul., Nurachmah, Elly, \& Adam,M. (2019). Faktor Penentu Kualitas Kompresi Resusitasi Jantung Paru Oleh Perawat. Volume 3 (2).

Astutik, Nurul, Puji. (2017). Hubungan Pengetahuan Bantuan Hidup Dasar (BHD) Dengan Motivasi Pada Polisi Lalu Lintas Dalam Memberikan Pertolongan Pada Korban Kecelakaan Lalu Lintas Di Kota Magetan.

Dharma, Kusuma Kelana (2015), Metodologi Penelitian Keperawatan : Panduan Melaksanakan dan Menerapkan Hasil Penelitian, Jakarta, Trans InfoMedia

Endiyono, \& Prasetyo, Rachmat. D. (2018). Pengaruh Latihan Basic Life Support Terhadap Pengetahuan dan Keterampilan Tim Muhammadiyah Disaster Management (MDMC) Banyumas. Universitas Muhammadiyah Purwokerto

Kaweenuttayanon, Nayawadee, dkk. (2017). Defining the Optimal Age for Basic Life Support and Cardiac Compression Training in Thai Adolescents. J Med Assoc Thai, 100 (9): 967-71

Kenney, W. Larry., dkk. (2015). Physiology of Sport and Exercise . Human Kinetics

Krammel, M., Schnaubelt, S., Weidenauer, D., Winnisch, M., Steininger, M., Eichelter, J., ... Sulzgruber, P. (2018). Gender and age-specific aspects of awareness and knowledge in basic life support. 1-9.

Lestari, Carlita (2015). Pengaruh Pelatihan Bantuan Hidup Dasar (BHD) Pada Remaja Terhadap Tingkat Pengetahuan Menolong Korban Henti Jantung. Yogyakarta : Program Studi Ilmu Keperawatan Universitas Muhammadiyah Yogyakarta

Mais, P. R., Mulyadi, \& Lolong, J. (2015). Pengaruh Penyuluhan Bahaya Gunung Berapi Terhadap Kesiapsiagaan Siswa SMP Kristen Kakaskasen Kota Tomohon Menghadapi Bencana Gunung Berapi. E-journal Keperawatan. Volume 3.

Mauri R, Burkart R, Benvenuti C, Caputo M, Moccetti T, Del Bufalo A et al. (2015). Better Management Of Out-Of-Hospital Cardiac Arrest Increases Survival Rate And Improves Neurological Outcome In The Swiss Canton Ticino. Europace. 18(3):398-404 
Ngirarung, S. A. A., Mulyadi, \& Malara, R. T. (2017). Pengaruh Simulasi Tindakan Resusitasi Jantung Paru (RJP) Terhadap Tingkat Motivasi Siswa Menolong Korban Henti Jantung Di SMA Negeri 9 Binsus. E-Journal Keperawatan, 5 (1), 1-8.

Patricia Gonce, Morton. (2013). Keperawatan Kritis: Pendekatan Asuhan Holistic. Jakarta: EGC

Perkins, G. D., Handley, A. J., Koster, R. W., Castrén, M., Smyth, M. A., Olasveengen, T., ... Greif, R. (2015). European Resuscitation Council Guidelines for Resuscitation 2015. Section 2. Adult basic life support and automated external defibrillation. Resuscitation, 95, 81-99. https://doi.org/10.1016/j.resuscitation.2015.07.015 diakses pada tanggal 15 Februari 2019

RISKESDAS. (2013). Badan Penelitian Dan Pengembangan Kesehatan Departemen Kesehatan Republik Indonesia. Jakarta

Saam Z, Wahyuni S. (2012). Psikologi Keperawatan (1st ed.). Jakarta: Rajawali Pers.

Sentana, A.D, dkk. (2018). Efektifitas Video CPR Terhadap Kemampuan Masyarakat Awam Dalam Melakukan CPR di Desa Sembung Kecamatan Narmada. Jurnal Kesehatan Prima. Volume $12(2), 134-144$

Silvana, T. S., \& Sumbawati, M. S. (2017). Hubungan Antara Motivasi Belajar dan Pembelajaran Berbasis Web pada Mata Pelajaran Simulasi dan Komunikasi Digital di SMK Negeri 2 Surabaya. Jurnal IT-EDU, 2(2), 57-66.

Suprapto Tommy. (2009). Pengantar Teori dan Manajemen Komunikasi. Cetakan ke 8. Yogyakarta: MedPress

Thoyyibah, D. Z. (2014). Pengaruh Pelatihan Bantuan Hidup Dasar Pada Remaja terhadap Tingkat Motivasi Menolong Korban Henti Jantung. (http://thesis.umy.ac.id/datapublik/t340 49.pdf/ diakses tanggal 26 Juni 2019)

Widyarani, L. (2018). Analisis Pengaruh Pelatihan Resusitasi Jantung Paru RJP Dewasa terhadap Retensi Pengetahuan dan Ketrampilan RJP pada Mahasiswa Keperawatan di Yogyakarta. Jurnal Keperawatan Soedirman, 12(3), 143. https://doi.org/10.20884/1.jks.2017.12.3.718

Yumniyati, Khisna. (2016). Pengaruh Jenis Kelamin Terhadap Kemampuan Berpikir Kreatif Siswa Kelas X Pada Materi Geometri Dikontrol dengan Kemampuan Spasial di SMAN 13 Semarang. 